\title{
Türkiye kivi bahçelerinde yeni bir zararlı, Metcalfa pruinosa (Say, 1830) (Hemiptera: Flatidae)
}

\author{
Ali GÜNCAN \\ Ordu Üniversitesi Ziraat Fakültesi, Bitki Koruma Bölümü, 52200-Ordu \\ Alınış tarihi: 07 Ocak 2015, Kabul tarihi: 15 Mart 2015 \\ Sorumlu Yazar: Ali GÜNCAN, e-posta:guncan.ali@gmail.com
}

\section{Öz}

Ordu ili kivi bahçelerinde 2014 yılı Haziran-Ağustos ayları arasında yapılan gözlemlerde, önemli bir istilacı tür olan Metcalfa pruinosa (Say, 1830) (Hemiptera: Flatidae) ile tespit edilmiştir. $\mathrm{Bu}$ çalışmada dünyada önemli bir kivi zararlısı olan bu polifag türün, Ordu ili kivi üretim alanlarındaki yayılışı verilmiştir. Sonuçlar zararlıya karşı yürütülecek savaş yöntemleri yönünden tartışılmıştır.

Anahtar kelimeler: Actinidia deliciosa, Kivi, Metcalfa pruinosa, Ordu, Türkiye

\section{Metcalfa pruinosa (Say, 1830) (Hemiptera: Flatidae), a new pest in kiwifruit orchards of Turkey}

\begin{abstract}
Citrus Flatid Planthopper, Metcalfa pruinosa (Say, 1830) (Hemiptera: Flatidae), an invasive pest, was found during the field surveys of kiwifruit orchards of Ordu Province (Turkey) between June and August 2014. Distribution of this polyphagous species, an important kiwifruit pest throughout the world, was given in kiwi production areas of Ordu. Results were discussed in terms of control methods against this pest.
\end{abstract}

Key words: Actinidia deliciosa, kiwifruit, Metcalfa pruinosa, Ordu, Turkey

\section{Giriş}

Anavatanı Çin olan kivi, Actinidia deliciosa (A. Chev.) C.F. Liang et A.R. Fergusson, (Actinidiaceae), dünyanın ılıman iklime sahip birçok bölgesinde yaygın olarak yetiştirilmektedir. Türkiye, dünya kivi üretiminde önemli bir yere sahip olma yolunda olup üretimini 1994 'te 7 tondan 2012 de 36800 tona çıkarmayı başarabilmiş ve Çin, İtalya, Yeni Zelanda, Şili, Yunanistan ve Fransa'nın ardından yedinci sıraya yükselmiștir (Bano and Scrimgeour, 2012; FAO, 2014; TUİK, 2014). Türkiye geneli incelendiğinde ise Türkiye İstatistik Kurumu'nun 2013 yll verilerine göre kivi üretiminde Yalova yaklaşık 18000 ton ile birinci, Rize yaklaşık 6270 ton ile ikinci ve Ordu yaklaşık 6070 ton ile üçüncü sırayı almaktadır (TÜİK, 2014). Türkiye'de 1988 yılında deneme aşamasında yetiştiriciliğine başlanan kivinin, günümüzde üretimi hızla artış göstermiş ve özellikle Doğu Karadeniz Bölgesi'nde vazgeçilmez olarak görülen çay ve fındığın yanında son yıllarda adından sıkça bahsettiren ekonomik getirisi yüksek bir meyve türü haline gelmiştir.

Diğer tarımsal ürünlerde olduğu gibi kivi yetiştiriciliği de, önemli verim kaybına neden olan hastalık, zararlı ve yabancı otlar gibi sorunlarla karşı karşıyadır. Dünyada kivide zararlı olduğu saptanmış böcek sayısı yaklaşık 50 kadardır (Steven, 1999). Türkiye'de tespit edilmiş zararlı böcek zararlıları ise; yazıcı böcekler Xyleborus dispar (Fabricius), Xyleborus xylographus (Say), Xylosandrus germanus (Blandford) ve Lymantor coryli (Perris) (Coleoptera: Scolytinae) (Ak ve ark., 2006; 2010; 2011) ve kabuklubitler Hemiberlesia rapax (Comstock), Pseudaulacaspis pentagona (Targioni Tozzetti), Ceroplastes sinensis Del Guercio, Coccus hesperidum L. 
olmak üzere kabuklubitler (Hemiptera: Coccoidea) (Ülgentürk ve ark., 2009) olmak üzere iki ana grup altında incelenebilir. Bunun dışında yine kivi de Ricania simulans (Walker) (Hemiptera: Ricaniidae) (Güçlü et al., 2010; Göktürk ve Aksu, 2014) ve Heliothrips haemorrhoidalis (Bouché) (Thysanoptera: Thripidae)'in (Ülgentürk ve ark., 2011) zararlı olduğu bildirilmektedir.

Ordu ili kivi bahçelerinde bulunan kabuklubit türlerini tespit etmek amacı ile 2014 yllında yürütülen proje kapsaminda yapılan incelemelerde kivi üretim alanlarında önemli bir istilacı tür olan Metcalfa pruinosa (Say, 1830) (Hemiptera: Flatidae) ile karşılaşılmıştır. Daha önce Karsavuran ve Güçlü (2004), tarafından İzmir ili mandarin bahçelerinde belirlenen bu tür kivi üretimi için yeni bir zararlı olması nedeni ile bu çalışmada ele alınarak zararlının Ordu ili kivi üretim alanlarındaki yayılış bilgileri verilmiş ve zararlıya karşı yürütülebilecek savaş yöntemleri yönünden tartışılmıştır.

\section{Materyal ve Yöntem}

Çalışma kapsamında kivi üretiminin yoğun olduğu Ordu ili merkez ve ilçelerinden 2014 yllı HaziranAğustos aylarında tesadüfi olarak seçilen 63 kivi bahçesinde gözlemler yapılmış ve örnekler alınmıştır (Çizelge 1). Buna göre Ordu genelinde bulunan tüm omcaların ortalama olarak \%1'i incelenmiștir. Gözlem yapılan bahçeler gözle kontrol edilerek bulaşıklık durumu tespit edilmiştir. Her bahçeden örnekler alınmış ve etiketlenerek kağıt torbalar içine konulup laboratuvara getirilmiştir. Örneklerde bulunan Metcalfa pruinosa erginleri \%70'lik alkole alınmıştır. Nimfler ise kaçışları engelleyecek şekilde tülle kaplı saksıda yetiştirilen kivi fidanlarında beslenemeye bırakılmış ve ergin olmaları beklenmiştir. Örnekler hazırlanarak tanılama için Dr. AndreaLucchi (University of Pisa, İtalya) ve Dr. Stephen Wilson (University of Central Missouri, ABD)'ya eş zamanlı gönderilerek teşhisi sağlanmıştır.

\section{Araştırma Bulguları ve Tartışma}

Çalışmada sörveyi yapılan toplam 63 bahçenin 13'ünün zararlının nimf ve erginleri ile bulaşı olduğu bulunmuştur (Çizelge 1). Örneklenen ilçelerin Gülyalı hariç tümünde bulaşıklık tespit edilmiştir. Bulaşık bahçe sayısı en fazla Fatsa ilçesinde, en az ise kivi üretimin büyük bir kısmının yapıldığı Altınordu ve Perşembe ilçelerinde karşılaşılmıştır. Ünye'de ise sekiz bahçenin dördünün zararlı ile bulaşık olduğu tespit edilmiştir.

Metcalfa pruinosa ilk kez 1979 yılında Kuzey Amerika'dan İtalya'ya bulaşmış (Zangheri and Donadini, 1980), daha sonra aralarında Türkiye'nin de bulunduğu 15 Avrupa ülkesinde hızla yayılmıștır (Strauss, 2010). Yayılışı kısa mesafelerde erginlerin uçma kabiliyetinin iyi olması ile daha uzun mesafelere ise bitki dokusuna koydukları yumurtaların bitkisel materyal ile taşınması şeklinde olmaktadır.

Çizelge 1. Ordu ilinde gözlem yapılan ilçeler, gözlem tarihleri, incelenen ve bulaşık bahçe sayıları

\begin{tabular}{lcccc}
\hline İlçeler & Toplam Ağaç sayısı & Gözlem Tarihleri (2014) & İncelenen bahçe sayısı & Bulaşık Bahçe sayısı \\
\hline Gülyalı & 19950 & 19 Haziran & 7 & 0 \\
Altınordu & 54600 & 26 Haziran, 03 Temmuz & 16 & 1 \\
Perșembe & 31800 & 10 Temmuz & 18 & 1 \\
Fatsa & 18700 & 14 Ağustos & 14 & 7 \\
Ünye & 13000 & 21 Ağustos & 8 & 4 \\
\hline TOPLAM & & & 63 & 13 \\
\hline
\end{tabular}

*TÜIK (2014)'e göre

Konukçu dizini oldukça fazla olan M. pruinosa, başta turunçgiller olmak üzere toplamda 200'ü aşkın bitki türünde konukçuluk yaptığı belirtilmektedir (Girolami et al., 1996). Türkiye'de ise ilk kez 2003 yılında İzmir ilinde mandarin bahçesinde rastlanılmıștır (Karsavuran ve Güçlü, 2004). Kivide zararlı olduğunu ise İtalya'da (Greatti and Girolami, 1994), Fransa'da (Hennion et al., 2003) ve Yunanistan'da (Souliotis et al., 2008; Navrozidis et al., 2009) tarafından bildirilmiştir.
Ergin ve nimflerin kivide bitki özsuyu ile beslenerek oluşturdukları doğrudan zararın yanısıra yoğun popülasyonlarda salgıladıkları tatlımsı madde ile neden oldukları fumajin ile özellikle meyvelerin ekonomik değerinin düşmesine neden olacağ düşünülmektedir. Tatlımsı madde salgılanması, 5 . dönem nimf ve ergin dönemlerinde dahada artmaktadır (Wilson and Lucchi, 2007) ve oluşan fumajinin başta kivi olmak üzere, kavun, Trabzon hurması, incir, ceviz ve elmanın meyvelerinde kaliteyi 
düşürdüğünü bildirilmiştir (Greatti and Girolami, 1994).

Çalışma esnasında herhangi bir doğal düşmana rastlanılmamıștır. Dünyada ise zararlının etkili parazitoiti, Neodryinus typhlocybae (Ashmead) (Hymenoptera: Dryinidae) 1987 yılında Kuzey Amerika'dan getirtilerek, İtalya'ya yerleștirilmiştir. Daha sonraları da Fransa, Slovenya, İsviçre, Hirvatistan, Yunanistan, Hollanda ve İspanya'ya parazitoitin salım çalışmaları yapılmış ve $M$. pruniosa'nın baskılanmasında günümüze kadar önemli bir faktör olmuştur (Strauss, 2010). Ergin dişi parazitoit, zararlının 3., 4. ve 5. dönem nimflerini parazitlemektedir. Ayrıca ergin parazitoitin genç dönem nimfler ile beslenme özelliği ise parazitoitin etkililiğini daha da önemli hale getirmektedir (Girolami et al., 1996). Ayrica Fulgoraecia barberiana Dyar (Lepidoptera: Epipyropidae)'nin larvalarının ise M. pruniosa'da parazit olarak yaşadığı bildirilmiştir (Wilson and McPherson, 1979). Bunun dişında Coccinella septempunctata L. (Coleoptera: Coccinellidae), Miridae (Hemiptera) ve Chrysopidae (Neuroptera) familyasına bağlı predatörlerin $M$. pruniosa ile beslendikleri çeşitli araştırıcılar tarafından belirtilmiştir (Barbattini et al. 1991; Greatti et al. 1994; Kahrer et al., 2009; Strauss, 2012). Biyolojik savaşın yanında Kahrer (2005), budamanın özellikle ince dallardaki çatlaklara bırakılan yumurtaların azaltılmasında önemli olduğunu belirtmiştir. Daha yüksek verim ve kaliteli ürün elde etmek için kivide düzenli budama oldukça önemlidir. Özellikle sert yapılan kış budamasında bu zararlının kışı geçiren yumurtaları dikkate alınarak yapılması popülasyonun düşmesini sağlanabilir. Bununla beraber yine nimflerin hedeflendiği kimyasal savaşımda zararlıyı baskı altına almakta oldukça etkili olduğu belirtilmiştir. Etkinin istenilen düzeyde olması için zamanlama en önemli faktördür (CABI, 2014). Ancak Türkiye'de kivi alanlarında herhangi bir zararlıya karşı henüz ruhsat alan bir bitki koruma ürünü bulunmamaktadır.

Ülkemize ilk kez 2003 yllında Ege Bölgesi'nde saptanan M. pruniosa, 2014 yllında kivi bahçelerinde tespit edilmiştir. Zararlı aktif uçma yeteneğinin kuvvetli ve konukçu dizininin geniş olması nedeniyle yayılma potansiyeli fazla olduğu yurtdışında yapılan çalışmalardan anlaşılmaktadır. Kivi üretiminin önemli olduğu Doğu Karadeniz Bölgesi'nde henüz zararlının tam anlamıyla yayılıșı, konukçuları ve biyolojisi bilinmemektedir. Önemli bir kivi zararlısı olma potansiyeli göz önüne alınarak, çevre ve insan sağlığı gözeterek zararlı ile mücadelede uygun tedbirlerin alınması gerekmektedir.

\section{Teşekkür}

Dr. Andrea Lucchi (University of Pisa, Italy) ve Dr. Stephen Wilson (University of Central Missouri, USA) Metcalfa pruinosa'nın tanılaması konusunda yardımları için teşekkür ederim.

\section{Kaynaklar}

Ak, K., Güçlü, Ş. ve Tuncer, C., 2010. Kivide yeni bir meyve zararlısı: Lymantor coryli (Perris, 1853) (Coleoptera: Scolytidae). Türkiye Entomoloji Dergisi, 34(3):391-397.

Ak, K., Saruhan, İ., Tuncer, C., Akyol, H. ve Kılıç, A. 2011. Ordu ili kivi bahçelerinde yazıcıböcek (Coleoptera: Scolytidae) türlerinin tespiti ve zarar oranları. Türkiye Entomoloji Bülteni, 1(4):229-234.

Ak, K., Uysal, M. ve Tuncer, C., 2006. Karadeniz Bölgesinde kivilerde zararlı yazıcıböcek (Coleoptera: Scolytidae) türleri ve mücadelesi. Gaziosmanpaşa Üniversitesi, Ziraat Fakültesi, II. Ulusal Kivi ve Üzümsü Meyveler Sempozyumu Bildirileri, Tokat, Türkiye, 14-16 Eylül, 365-370.

Bano, S. and Scrimgeour, F., 2012. The export growth and revealed comparative advantage of the New Zealand kiwifruit industry. International Business Research, 5(2):73-82.

Barbattini R.,Greatti M., Iob M., Sabatini A.G., Marcazzan G. and Colombo R., 1991. Osservazioni su Metcalfa pruinosa (Say) e indagine sulle caratteristiche del miele derivato dalla sua melata. Apicoltura 7: 113135.

CABI, 2014. Metcalfa pruinosa. (Preventionand Control) In: Invasive Species Compendium. Wallingford, UK: CAB International. www.cabi.org/isc. (Erişim Tarihi: 18 Ekim 2014)

FAO, 2014. Food and Agriculture Organization, FAOSTAT, http://faostat3.fao.org/ (Erişim Tarihi: 15 Haziran 2014).

Girolami V., Conte L., Camporese P., Benuzzi M., Martir G.R. and Dradi D, 1996. Possibilita di controllo biologico della Metcalfa pruinosa. Informatore Agrario, 52:25.

Göktürk, T. ve Aksu, Y. 2014. Tarım ve orman alanlarında zarar yapan Ricania simulans (Walker) 1851 (Hemiptera: Ricaniidae)'un morfolojisi, biyolojisi ve zararı. 2014. Türkiye II. Orman Entomolojisi ve Patolojisi Sempozyumu. Antalya, Türkiye, 07-09 Nisan, 279-281.

Greatti M., Zandigiacomo P. and Rossi L., 1994. Predatori di Metcalfa pruinosa (Say) in Friuli. Atti XVII Cong Naz It Entomologia, Udine, Italy, 13-18 June, 535-538. 
Greatti M. and Girolami V., 1994. Efficacia di soluzioni dilavanti nel controllo degli stadi giovanili di Metcalfa pruinosa (Say). L'Informatore Agrario, 50 (21): 77-79.

Güçlü, Ş., Ak, K., Eken, C., Akyol, H., Sekban, R., Beytut, B. and Yıldırım, R. 2010. Pathogenicity of Lecanicillium muscarium against Ricania simulans. Bulletin of Insectology. 63 (2): 243-246.

Hennion, B., Lecomte, P., Larignon, P., Baudry, A., Durpaire, M.P., Mouillon, M., Tailleur, J.L. and Dupuy, O. 2003. First observations of a wood decay (esca-like disease) on kiwifruit in France. Acta Horticulturae, 610:409-413.

Kahrer, A. 2005. Introduction and possible spread of Metcalfa pruinosa (Cicadina; Flatidae) in Austria. Plant Protection and Plant Health in Europe: Introduction and Spread of Invasive Species, Symposium, Humboldt University, Berlin, Germany, 9-11 June, 133-134.

Kahrer, A., Strauss, G., Stolz, M. and Moosbeckhofer, R. 2009. Beobachtung zur Faunistik and Biologie der vor kurzem nach Österreich eingeschleppten Bläulingszikade (Metcalfa pruinosa). Beiträge zur Entomofaunistik, 10: 17-30.

Karsavuran Y. ve Güçlü, S. 2004. Türkiye faunası için yeni bir zararlı tür, Metcalfa pruinosa (Say, 1830) (Homoptera: Flatidae). Türkiye Entomoloji Dergisi, 28(3):209-212.

Navrozidis, E., Zartaloudis, Z. and Vartholomaiou, A. 2009. The appearance of Metcalfa pruinosa (Say) on kiwi culture and control efforts at Pierias perfecture. Italus Hortus, 16(5): 240.

Souliotis, C., Papanikolaou, N.E., Papachristos, D. and Fatouros, N. 2008. Host plants of the planthopper Metcalfa pruinosa (Say) (Hemiptera: Flatidae) and observations on its phenology in Greece. Hellenic Plant Protection Journal, 1(1): 39-41.

Steven, D., 1999. Integrated and organic production of kiwifruit. Acta Horticulturae, 498: 345-354.

Strauss, G. 2010. Pest risk analysis of Metcalfa pruinosa in Austria. Journal of Pest Science, 83(4), 381-390.

Strauss, G. 2012. Environmental risk assessment for Neodryinus typhlocybae, biological control agent against Metcalfa pruinosa, for Austria. European Journal of Environmental Sciences, 2(2): 102-109.

TUİK, 2014. Türkiye İstatistik Kurumu. Bitkisel Üretim İstatistikleri. http://www.tuik.gov.tr, (Erişim Tarihi:25 Haziran 2014).

Ülgentürk, S., Ayhan, B. ve Karakaya, A. 2009. Rize ili kivi bahçelerinde görülen kabuklubitler ve koşniller (Hemiptera: Coccoidea). Uludağ Üniversitesi Ziraat Fakültesi Dergisi. 23(1):55-60.

Ülgentürk, S., Ayhan, B., Karakaya, A. ve Tunç, İ. 2011. Türkiye'de yeni bir kivi zararlısı: Sera Thripsi Heliothrips haemorrhoidalis (Bouché) (Thysanoptera: Thripidae). Uludağ Üniversitesi Ziraat Fakültesi Dergisi. 25(1): 143-149.

Wilson, S.W. and McPherson, J.E. 1979. Notes on the occurrence of Epipyrops barberiana in southern Illinois (Lepidoptera: Epipyropidae). The Great Lakes Entomologist, 12(4):189-190.

Wilson, S.W. and Lucchi, A. 2007. Feeding activity of the flatid planthopper Metcalfa pruinosa (Hemiptera: Fulgoroidea). Journal of the Kansas Entomological Society, 80(2): 175-178.

Zangheri, S. and P. Donadini. 1980. Comparsa nel Veneto di un omottero neartico: Metcalfa pruinosa Say (Homoptera, Flatidae). Redia, 63: 301-305. 